\title{
Velhice(s) e participação em estruturas residenciais para idosos percecionadas por pessoas idosas e assistentes sociais: um estudo qualitativo
}

\section{Aging heterogeneity and participation in residential structures for older people perceived by older adults and social workers: A qualitative study}

\section{Ricardo Crispim (1)}

(1) Sta Casa Misericórdia, Leiria, Portugal

Recebido: 02/05/2020; Revisto: 24/05/2020; Aceite: 28/05/2020.

https://doi.org/10.31211/rpics.2020.6.1.172

\begin{abstract}
Resumo
Objetivo: Esta investigação tem como objetivo trazer uma reflexão sobre as várias expressões da(s) velhice(s), associadas à participação ativa das pessoas idosas em Estruturas Residenciais para Idosos (ERPI) e no seu projeto de vida. Método: A amostra envolveu 12 pessoas idosas e cinco assistentes sociais que residiam e exerciam a prática profissional em ERPI, respetivamente. $O$ protocolo foi composto por questionário sociodemográfico e entrevistas em profundidade (semiestruturada), prosseguindo uma abordagem qualitativa (análise de conteúdo). Resultados: A amostra de pessoas idosas constitui-se maioritariamente por "idosos muito idosos" (> 85 anos). A participação nos processos decisórios em ERPI tenderam a inclinar-se para a renúncia voluntária das pessoas idosas em contribuir para as decisões alocadas às dinâmicas/estratégias institucionais. Na posição adotada pelas ERPI, ainda que estas assumam um padrão diretivo associado ao cuidado, começam a surgir disposições que apresentam um carácter mais inovador (e.g., comissões de idosos, biblioterapia, tertúlias), convergindo com as abordagens atuais do envelhecimento ativo, em que as pessoas idosas são reconhecidas como um coletivo heterogéneo. Este facto encontra paralelo com a expressão da satisfação dos seniores, advinda da oportunidade que lhes é dada de exercerem quotidianamente a sua cidadania. Conclusões: $\mathrm{O}$ cuidado institucional tende a privilegiar uma abordagem holística no entendimento da(s) velhice(s). Estas alterações, ainda que assumam um ritmo lento e monótono, fazem emergir abordagens operativas capazes de privilegiar o capital de conhecimento e sabedoria das pessoas idosas implicando-as ativamente nos processos decisórios em contextos residenciais coletivos, associadas aos movimentos contemporâneos do envelhecimento ativo.
\end{abstract}

Palavras-Chave: Heterogeneidade da(s) velhice(s); Participação; Estruturas Residenciais para Idosos; Pessoas idosas; Estudo qualitativo.

\section{DI\&D | ISMT}

rpics@ismt.pt

https://rpics.ismt.pt distribuído sob a Licença Creative Commons Attribution, que permite uso, distribuição e reprodução sem restrições em qualquer meio, desde que o trabalho original seja devidamente citado.
Ricardo Miguel da Silva Crispim

Santa Casa da Misericórdia de Leiria,

Leiria, Portugal

E-mail: rmscrispim@hotmail.com 


\begin{abstract}
Aim: This investigation aims to bring a reflection on the various expressions of old age heterogeneity, associated with the active participation of the older people in Residential Structures for the Older People (ERPI) and in their life project. Method: The sample involved 12 older people and five Social Workers who lived and practiced their profession in ERPI, respectively. The protocol consisted of a Sociodemographic Questionnaire, and (semi-structured) In-Depth Interviews, using a qualitative approach (content analysis methodology). Results: In the sample of older adults, the majority were "old-old" adults (> 85 years old). Concerning participation in ERPI decision-making processes, older people voluntarily refused to contribute to the decisions allocated to the institutional dynamics/strategies. Regarding the position adopted by ERPIs, even though they assume a directive pattern associated with care, provisions having a more innovative nature (e.g., older people's committee, bibliotherapy, social gatherings) begin to emerge, converging with current approaches of active aging, in which, older people are recognized as a heterogeneous group. This fact is in line with the senior citizens' fulfillment that arises from the opportunity they are given to exercise their citizenship daily. Conclusions: Institutional care tends to favor a holistic/global approach to understanding old age heterogeneity. These changes, although assuming a slow and monotonous pace, lead to operational approaches capable of privileging the knowledge and wisdom of the older people, actively involving them in decision-making processes in collective residential contexts, associated with the contemporary active aging movements.
\end{abstract}

Keywords: Heterogeneity of old age; Participation; Residential Structures for the Older People; Older People; Qualitative study.

\title{
Introdução
}

Consequência do crescimento populacional que caracterizou o século $X X$ e da estabilização ou até mesmo declínio populacional e envelhecimento da população do século XXI (consequência do declínio da natalidade e do aumento da duração média de vida), resultou, entre outros, o envelhecimento demográfico (e.g., Fernandes, 2011). Este fenómeno traduz atualmente um desafio de alcance mundial, configurando-se como uma nova e moderna realidade. Este fenómeno convoca de maneira crescente a procura e o apoio fornecido junto das Estruturas Residenciais para Idosos (ERPI). Neste contexto, as abordagens associadas às várias expressões da velhice e à experienciação da participação das pessoas idosas (i.e., naquilo que tem de ver com os processos de tomada de decisão das pessoas idosas) em ERPI, revelam ser elementos preditores de elevada relevância, no que concerne à satisfação com os serviços e com a vida. Em concreto, tal significa, que a participação na senescência associada à experienciação da velhice em ERPI, constituem fatores distintivos, que se mostram inerentes ao incremento da qualidade de vida das pessoas idosas.

\section{Velhice "longeva": Indicadores e tendências no século XXI}

O fenómeno do envelhecimento demográfico, caracterizado pelo aumento do número das pessoas idosas na população total, ocorreu e continua a ocorrer no século XXI, de forma galopante, na maioria das zonas do globo (e.g., Rosa, 2020). Dados recentes revelam que o envelhecimento demográfico, por exemplo, na União Europeia $(U E)$, trará impactos muito significativos nas próximas décadas, não só porque é claro o declínio perigoso da fecundidade e a esperança de vida à nascença é francamente elevada, mas também devido ao aumento do índice de longevidade e aos baixos níveis da mortalidade em idades avançadas (i.e., permitindo que as pessoas vivam mais tempo) (e.g., Cabral, 2017; Eurostat, 2019; Rosa, 2018). Face ao exposto, assiste-se a uma inversão quase perfeita das classes etárias que caracterizam a pirâmide etária, o que decorre do facto de em muitos dos países industrializados não se assistir a uma reposição das gerações, ficando estas abaixo do equilíbrio estatístico (e.g., Cabral, 2017). Esta inversão da pirâmide etária conduz a par, e nos termos de Mendes (2017), a uma crescente escassez de crianças/adolescentes e mesmo de jovens adultos. Em suma, estas variáveis demográficas traduzem 
indicadores que mudaram significativamente, tendo conduzido a uma mudança no perfil etário da sociedade, a qual não apenas envelheceu, como também se tornou mais longeva (Rosa, 2020).

Neste enquadramento, o envelhecimento progressivo da população idosa e o avolumar dos idosos muito idosos (i.e., pessoas com mais de 85 anos) tende a ser uma marca societal (Cabral, 2017). Como os indicadores informam, este é o segmento que tem vindo a crescer ao ritmo mais acelerado comparativamente a qualquer outro segmento etário populacional. Neste sentido, prevê-se que a percentagem das pessoas com 80 anos de idade ou mais, na população dos 28 países que constituem a UE, mais do que duplique, entre 2017 e 2080, passando de 5,5\% para 12,7\% (Eurostat, 2019), respetivamente.

Para o caso português e de acordo com a Pordata (2020a), tem-se vindo a registar um aumento acentuado do número de pessoas com 65 ou mais anos, sobretudo a partir da década de 70 do século XX, com maior expressividade nas pessoas idosas do sexo feminino (Pordata, 2020b, 2020c). Neste contexto e segundo as “Projeções de População Residente, 2015-2080" (Instituto Nacional de Estatística [INE], 2019), em Portugal irá intensificar-se o envelhecimento da população, tendendo o número de pessoas idosas a evoluir, de 2,1 (2015) para 2,8 milhões (2080)1. De salientar, que tendo por base os indicadores mais recentes, Portugal é o terceiro país mais envelhecido do mundo (Pordata, 2020d) e aquele onde o segmento dos "idosos muito idosos" mais cresce (e.g., Rosa, 2020).

\section{Heterogeneidade da(s) velhice(s): Elementos em construção concetual}

O conceito de heterogeneidade da(s) velhice(s) agrega em si uma multiplicidade de sentidos, assente na ideia de se equacionar as suas múltiplas dimensões e facetas, constatando-se pelas bastas investigações que a população com mais de 65 anos não é homogénea, mas que ao invés, se pauta pela diversidade e diferenciação, obrigando, por tal razão, a reconfigurar o ciclo vital e, por conseguinte, a reconcetualizar o conceito de velhice (e.g., Brandão et al., 2017). Neste seguimento aludimos a duas variáveis distintivas: a leitura convencional e a leitura assente na ideia do envelhecimento diferencial.

Numa leitura convencional centrada na ideia do envelhecimento demográfico remete-nos para duas variáveis: uma primeira para fatores de homogeneização, resultado de dinâmicas de discriminação etária prevalentes, em grande medida, nas sociedades contemporâneas; a segunda associa-se aos riscos experienciados pelas pessoas idosas, quer referentes ao acesso a bens materiais, equipamentos, serviços e oportunidades sociais (e.g., educação e saúde), quer à participação das pessoas idosas nas respetivas sociedades de que são membros (e.g., Nogueira et al., 2016; Sousa \& Batista, 2015; Stephens et al., 2015). Observa-se que tal cenário concorre para o engrandecimento do fenómeno do idadismo (ageism na língua anglo-saxónica), termo este que é utilizado para dar conta do fenómeno discriminatório face à idade.

O ethos social (i.e., valores morais que balizam um dado período social histórico) assente nas conceções biomédicas associadas ao envelhecimento (i.e., noção de que o envelhecimento resulta essencialmente de fatores biológicos e genéticos) e a noção tradicional de velhice que vigora em grande medida nas sociedades pósmodernas, associa ao processo de senescência a deterioração, a patologias, a perda de faculdades, a insuficiência, a inadequação, ao empobrecimento, a ineficácia e a senilidade, aliando a pessoa idosa a vertentes relacionadas com a inutilidade, a fragilidade, a incapacidade, a dependência e a tomada a cargo (Daniel et al., 2012; Dionigi, 2015; Júnior et al., 2017; Mendes et al., 2018). Ora, em termos genéricos, segundo alguns autores (e.g., Dionigi,

1 Prevê-se que, face ao decréscimo da população jovem, o índice de envelhecimento venha a duplicar, passando de 147 (2015) para 317 idosos, por cada 100 jovens, em 2080 (INE, 2019). 
2015; Mendes et al., 2018; Miguel, 2016), conotações deste tipo (essencialmente negativas e na maioria das vezes rígidas e erróneas) conferem às pessoas idosas maior vulnerabilidade no seu estado de saúde, maior isolamento social e solidão, dependência física, mental e também económica; bem como aumenta em número e tipologia os abusos físicos, psicológicos, sexuais, financeiros ou materiais, afetando física, económica, social e psicologicamente o bem-estar das pessoas idosas, excluindo-as e denegrindo-as (Lima, 2010; Mendes et al., 2018). Acresce maior negatividade às pessoas idosas que recorrem aos cuidados institucionais (e.g., Fagundes, et al., 2017). Em resumo, colocar no mesmo segmento concetual todas as pessoas com 65 ou mais anos, sem considerar a especificidade de cada elemento, tira-Ihes poder, aumenta a imagem estereotipada e reduz sobremaneira as especificidades e a diversidade no seu interior (Pinto, 2013).

Numa leitura assente na lógica do envelhecimento diferencial, convocamos o contributo de Birren (1995) quanto refere que o envelhecimento é um processo ecológico, resultante da interação entre organismos/sistemas com um determinado património genético e diversos meios físicos, sociais, históricos e culturais.

(...) o que quer dizer que os fatores biológicos e genéticos não asseguram, por si só, a expressão ótima do desenvolvimento humano [e que] a passagem dos anos e a acumulação de experiências, os idosos acentuam as suas diferenças de origem, sublinhando as competências ou as incapacidades que a sua base genética, em interação com o meio, permite expressar (Fonseca, 2006, p. 75).

Neste seguimento, estamos capazes de afirmar que o envelhecimento é um processo bastante individualizado que varia substancialmente entre indivíduos, que resulta das vivências pessoais de cada sujeito e das experiências adquiridas ao longo da vida; apresentando, por tal razão, múltiplas expressões, pelo que a variabilidade interindividual das pessoas idosas tende a ser superior à de outros grupos etários (Rosa, 2018; Simões \& Sapeta, 2017). Ou seja, estamos perante um coletivo heterogéneo, não estático nem uniforme e profundamente dinâmico e relativo, no ponto de vista das práticas sociais, das representações simbólicas e das expetativas face à vida e ao futuro. Neste seguimento importa questionar: podemos analisar este fenómeno enquanto velhice ou enquanto velhices?

Nesta linha de argumentação deve perder protagonismo a idade cronológica como elemento primeiro relativamente aos processos diferenciais de envelhecimento, sendo mais pertinente recorrer a classificações que obriguem a privilegiar a variabilidade dos estados/situações de velhice, assentes nas diferentes idades da velhice, nas "diferentes velhices" e na pluralidade de gerações mais idosas. Os processos de envelhecimento, percursos de vida, potencialidades e necessidades e expetativas das gerações mais idosas são diferentes de indivíduo para indivíduo e não podem ser descurados (e.g., Luz, 2017).

Importa deste modo falar de velhices e não de velhice, sendo que esta análise compreensiva induz a outras segmentações (Luz, 2017; Simões \& Sapeta, 2017). De entre a panóplia analítica existente adquirem particular relevo as noções de terceira e quarta idade, as quais se reportam essencialmente à ideia de condição física e funcionalidade sensorial e intelectual, reduzindo a importância da idade cronológica (e.g., Baltes \& Smith, 2003; Fonseca, 2006).

Em termos gerais Laslett (1994), Smith (2002) e Baltes e Smith (2003) referem que a transição da terceira para a quarta idade tem por base parâmetros de natureza individual (i.e., específica para cada sujeito) ainda que tenha de existir enquadramento ecológico e contextual nesta equação. Assim, o conceito de terceira idade está frequentemente associado a designações positivas (Laslett, 1994). Ou seja, nesta variável cabem os aspetos mais positivos que identificam os indivíduos com as condições e práticas de uma vida ainda autónoma e com elevados indicadores de plasticidade e capacidade de transformar perdas em oportunidades. 
Por sua vez, a quarta idade é relacionada a discursos mais negativos onde, acompanhadas de patologias, poucas são as funções que permanecem robustas associadas à fase mais tardia da vida (Laslett, 1994). Baltes e Smith (2003) explicam a quarta idade configurando-a como uma realidade diferente pautada por perdas qualitativas variadas (e não apenas quantitativas), com menor qualidade de vida e um estatuto funcional mais pobre não apenas em termos físicos, mas também psicológico e social colocando bastas limitações ao nível da participação e decisão das pessoas idosas, comprometendo o exercício da sua cidadania. Ou seja, a quarta idade não é uma mera continuidade da terceira idade, havendo entre as pessoas mais idosas e/ou na velhice mais tardia uma prevalência de disfunções e reduzida funcionalidade (e.g., Berlin Aging Study - BASE tal como citado em Fonseca, 2006).

Para Luz (2017) a diferenciação individual, coletiva e institucional da velhice tende a ter em consideração os aspetos do ser, do estar e do fazer. No campo do ser são valorizadas as identidades plurais na velhice, reconhecendo-se que existem diferentes idades para se ser velho e diferentes tipologias de idades, ganhando destaque o plano da cognição, funcionalidade, participação social, existência de suporte familiar, entre outros. No domínio do estar advoga-se a importância de se falar não de velhice, mas de velhices evidenciando-se a multidimensionalidade dos estados ou condições de se estar na velhice, uma vez que as vivências e percursos entre indivíduos são distintos. A dimensão do fazer obriga a reequacionar os riscos negativos da velhice (i.e., inatividade, passividade, dependência), mas sobremaneira as oportunidades e talentos como recurso.

É, pois, neste novo panorama de compreensão e reconfiguração das várias idades da velhice que se têm desenhado um paradigma mais positivo acerca do envelhecimento, tentando refutar o anterior entendimento centrado no declínio e perdas das pessoas mais velhas. Não obstante, a incidência crescente do envelhecimento e o avolumar do número de pessoas idosas eleva também a discussão acerca da forma como as mesmas se adaptam a diferentes papéis, normas e expectativas, bem como, à forma como as sociedades, as comunidades e o conjunto de organismos do terceiro setor interagem com as pessoas mais velhas, assim como o inverso (e.g., Miguel, 2016; Sousa \& Batista, 2015).

\section{Participação das pessoas idosas: Pistas e encruzilhadas nos caminhos das ERPI}

A abordagem da temática da participação, associada ao Envelhecimento Ativo (EA), envolvendo a população idosa, não constitui um exercício teórico e prático frequente e sobretudo em contextos residenciais (e.g., Gustavsson et al., 2015; Rede Europeia Anti-Pobreza/Portugal [REAP], 2017). Esta infrequência é decorrente do facto de ainda permanecer relativamente aos mais velhos o estereótipo de que estes, e de forma muito particular das pessoas idosas que residem em contextos residenciais, são pessoas desinteressadas por uma ampla gama de questões, designadamente, de natureza política, social e cultural e que se encontram estagnados e ultrapassados pela modernidade do tempo (Pinto, 2013).

Neste sentido, e como informa as Nações Unidas (2002), o EA traduz um conceito que não se aplica apenas às questões relacionadas com a manutenção de um nível de atividade física que promova a saúde, previna doenças e garanta a produtividade em idades avançadas. O EA carece, também de contemplar outras questões como aquelas associadas aos conceitos de cidadania ativa, empoderamento ou mesmo ativação.

Hoje, é amplamente reconhecido que a participação das pessoas idosas na tomada de decisões sociais e políticas é, não só, desejável, mas essencial em qualquer sistema democrático. No entanto, ainda não foi estabelecido qualquer acordo sobre o que significa essa participação, ou seja, o que é que os termos participação e pessoas 
idosas querem dizer em questões que os afetam, interessam e envolvem e muito menos em contextos residenciais (Dehi \& Mohammadi, 2020; Hees et al., 2015).

A conceção de participação e a distinção de intervenção micro, macro e meso contribui para a compreensão dos diferentes níveis da prática participativa e da relevância e potencial das atividades associadas à participação. Esta perspetiva é convergente com o pensamento de vários autores (Almeida, 2017; Dehi \& Mohammadi, 2020; Vieira, 2017), os quais enfatizam a participação como sendo um lugar de ação política alargada, interativa e dinâmica (i.e., negociada), comprometida entre vários interlocutores (e.g., de forma muito particular dos destinatários da ação) e ambientes, assente num processo pedagógico e democrático de permanente aprendizagem. Este tem em vista a (re)construção de oportunidades de desenvolvimento, de cidadania e de melhoria da tomada de decisão pessoal e social, por forma a serem atingidos níveis satisfatórios de autodeterminação, autocapacitação, empoderamento e protagonismo (Almeida, 2017; Dehi \& Mohammadi, 2020; Vieira, 2017). Por tal razão, a ação participativa não pressupõe que os interlocutores apenas "estejam presentes em", mas antes influenciem ativamente decisões e "ações" 2 com base nas suas opiniões.

Em contextos residenciais a participação das pessoas idosas constitui um tema parcamente explorado e defendido (REAP, 2017; Gustavsson et al., 2015). Assim, apesar de na institucionalização ainda existirem constrangimentos vários (i.e., cuidados sociais pouco flexíveis assentes numa esfera paliativa concentrada na saúde e na segurança), inviabilizadores da participação, urge caminhar nestes ambientes em direção a este desiderato; reforçando o exercício dos direitos e deveres das pessoas idosas, respeitando a sua idiossincrasia, favorecendo e (re)compondo e/ou fortalecendo os laços sociais das pessoas idosas com as redes envolventes e, mais importante, resgatando e perpetuando a cidadania das pessoas idosas (Brandão et al., 2017; Luz, 2017; Marchand, 2017; Marier \& van Pevenage, 2017; Reed et al., 2003; Rosa, 2018). A existência e perpetuamento de modelos rígidos no cuidado em estruturas residenciais concorrem, por um lado, para o aumento do conflito entre as pessoas idosas a residir em ERPI e os sistemas de apoio. Por outro lado, reduzem a margem de independência das pessoas idosas, diminuem a autonomia e a capacidade de tomada de decisão, o autoconceito e autoestima, a privacidade, o sentido de pertença e o bem-estar, tornando as pessoas idosas mais apáticas e passivas (Alaphilippe \& Bailly, 2014; HerazoBeltrán et al., 2017; Medeiros et al., 2020; Nogueira et al., 2016).

Em virtude da atual realidade social, surge dificultada a ativação das pessoas idosas enquanto agentes dinâmicos no design de políticas sociais no campo da Gerontologia e nas dinâmicas intrainstitucionais em contexto residencial (e.g., Crispim \& Almeida, 2019). A este nível, conforme alguns estudos (Crispim, 2020; Marchand, 2017; Reed et al., 2003), dois fatores podem ser apontados para essa realidade, designadamente de natureza exógena e endógena. Os primeiros referem-se a fatores liderados pelas famílias, os amigos, a comunidade e os profissionais, os quais quando toldados pela conceção clássica de velhice retiram poder simbólico às pessoas idosas (nomeadamente aqueles que padecem de algum tipo de psicopatologia e/ou deficiência motora), tendendo a não reconhecer valor nem utilidade às pessoas idosas. Além disto, sob o pretexto da ajuda e da proteção excessiva, assiste-se aquilo a que Pinto (2013, p. 55) define por "paternalismo invalidante". Este fenómeno, entre outras coisas, enfraquece os laços sociais com a rede de suporte familiar e comunitária e retira poder de decisão e de participação das pessoas idosas. No que concerne aos fatores endógenos, são relevantes os discursos proferidos pelas pessoas idosas, associados à perceção da sua velhice como negativa, reportando-se 
os mesmos frequentemente às suas limitações físicas, às experiências negativas e à noção de subserviência ou de "Agora é tempo de gozar a vida e de ser servido". Estes últimos fatores levam as pessoas idosas a auto excluíremse e a demitirem-se da lógica de "aprendizes". Nesta linha de ideias e seguindo Azeredo (2016), a sociedade deve permitir a inclusão das pessoas idosas e criar a oportunidade de se implicarem na dinâmica comunitária enquanto agentes sociais e de educação, mas, por sua vez, também as pessoas idosas devem tomar a iniciativa da mudança. A este respeito, são as pessoas idosas, a par com a comunidade onde estão inseridos, responsáveis pela alteração do paradigma negativo que os desvaloriza social e culturalmente (i.e., em países industrializados) (e.g., Azeredo, 2016). Para tal, é urgente um ethos do novo plasmado na ideia das pessoas idosas se demarcarem da imagem tradicional de velhice representada pela inutilidade, ineficiência e senilidade. Segue-se, então, que o estatuto social que as pessoas idosas gozam, muito embora dependa dos significados atribuídos pela sociedade, obedece também à narrativa que os próprios empregam à sua historicidade, ao seu presente e à forma como querem projetar a sua vida no futuro.

No presente existem múltiplas propostas, desafios e oportunidades para o EA e, naturalmente, às políticas setoriais são exigidas sobretudo soluções adaptativas centradas na especificidade de cada caso, grupo ou comunidade, quanto às abordagens nos processos e na ação das organizações direcionadas para as pessoas idosas (Luz, 2017). O exercício de reconfiguração da ação na realidade gerontoinstitucional é primordial, suscitando, neste caso particular às ERPI, a adoção de uma postura de maior abertura a novas práticas e modelos a fim de garantir a qualidade de vida de todas as pessoas idosas que abrange.

Face à problemática apresentada, o objetivo principal deste estudo é examinar à luz das expressões contemporâneas da velhice, a participação ativa das pessoas idosas em ERPI e no seu projeto de vida à luz de contributos de residentes e assistentes sociais que vivem e laboram em respostas sociais residenciais, respetivamente.

\section{Método}

\section{Desenho do Estudo}

Este estudo foi conduzido a partir de uma metodologia de natureza qualitativa. A opção pela metodologia qualitativa deveu-se ao facto desta nos permitir aceder a uma visão mais aprofundada, por um lado acerca das perspetivas dos assistentes sociais a laborar em contexto de ERPI no exercício da promoção da ativação das pessoas idosas em ambientes institucionais. Por outro lado, para possibilitar uma visão mais aprofundada acerca das perceções e por conseguinte da realidade experienciada pelas pessoas idosas que residem em ERPI quanto à sua participação em dinâmicas associadas ao seu projeto de vida em instituição e à participação ativa nas dinâmicas e estratégias internas da ERPI. Foi ainda usada uma metodologia quantitativa simples, que permitiu fazer descrições recorrendo ao tratamento estatístico dos dados recolhidos.

\section{Considerações éticas}

Um consentimento informado, esclarecido e livre para participação em estudo de investigação foi lido e assinado em duplicado por todos os participantes do presente estudo, com a finalidade de assegurar a confidencialidade e anonimato dos dados que foram recolhidos para fins de investigação. 


\section{Participantes}

Os participantes foram recrutados de cinco ERPI no ano de 2019. De salientar que o processo de seleção da amostra procurou reunir ERPI cuja atividade a nível de ações, políticas, programas e projetos fosse capaz de envolver as pessoas idosas em papéis de decisão na ação institucional. Assim, tendo por base uma pesquisa por via da internet (i.e., motor de busca da Google através da evocação de expressões como "comissão de residentes» ou «comissão de idosos»), bem como decorrente de conhecimentos do autor relativo a algumas ERPI, foi possível selecionar as instituições.

A amostra de conveniência ficou constituída por 12 pessoas idosas (10 do sexo feminino e 2 do sexo masculino) e cinco assistentes sociais (a totalidade do sexo feminino). Foram, em primeira instância, contactadas as direções das ERPI, explicitando os objetivos do estudo e solicitada a colaboração para a aplicação dos questionários/entrevistas. Os critérios de inclusão definidos foram, no caso das pessoas idosas, residirem na ERPI há três ou mais anos e não apresentarem comprometimento mental/cognitivo. Quanto às assistentes sociais, estas deveriam ter habilitações literárias em Serviço Social (i.e., licenciatura) e exercer atividade profissional em contexto residencial de prestação de cuidados a pessoas idosas há três ou mais anos.

$\mathrm{Na}$ amostra das pessoas idosas, as idades cronológicas dos participantes oscilaram entre os 80 e os 93 anos, sendo a média de 96,16 anos. Já a média de idades das assistentes sociais oscilava entre os 34 e os 57 anos, sendo a média de 44,4 anos, a desempenhar funções no quadro técnico ou da direção técnica organizacional das estruturas, em média há 14,7 anos. A Tabela 1 apresenta uma caracterização mais detalhada do grupo de estudo das pessoas idosas.

\section{Tabela 1}

Caracterização Sociodemográfica da Amostra das Pessoas Idosas

\begin{tabular}{|c|c|c|c|}
\hline & & $n$ & $\%$ \\
\hline \multirow{2}{*}{ Sexo } & Feminino & 10 & 83 \\
\hline & Masculino & 2 & 17 \\
\hline \multirow{3}{*}{ Estado civil } & Solteiro(a) & 2 & 14 \\
\hline & Viúvo(a) & 7 & 58 \\
\hline & Separado(a)/Divorciado(a) & 3 & 25 \\
\hline \multirow{5}{*}{ Habilitações literárias } & Analfabeto(a) & 2 & 17 \\
\hline & Sabe ler e escrever, mas não frequentou escola & 1 & 8 \\
\hline & 10 Ciclo & 6 & 50 \\
\hline & 3으디o & 2 & 17 \\
\hline & Ensino Superior & 1 & 8 \\
\hline \multirow{2}{*}{$\begin{array}{l}\text { Condição física e cognitiva } \\
\text { atual }\end{array}$} & Autónomo/a e funcional & 8 & 67 \\
\hline & Autónomo/a e funcional, mas mobiliza-se com materiais de apoio & 4 & 33 \\
\hline \multirow{3}{*}{$\begin{array}{l}\text { Processo de tomada de } \\
\text { decisão relativa à } \\
\text { institucionalização }\end{array}$} & Decisão própria & 9 & 75 \\
\hline & Decisão partilhada com familiares & 2 & 17 \\
\hline & Decisão da família & 1 & 8 \\
\hline
\end{tabular}




\section{Procedimento de recolha de dados}

A recolha dos dados foi realizada entre os dias 11 e 18 de novembro de 2019, nos concelhos de Alcácer do Sal, Campo Maior, Montemor-O-Velho, Leiria e Lisboa.

Em termos de instrumentos de recolha de dados, este estudo beneficiou do questionário sociodemográfico (visando recolher informações relativas à idade, sexo, estado civil, habilitações literárias, profissão) e de entrevistas em profundidade (semiestruturada) contemplando perguntas abertas e fechadas.

A entrevista aplicada às assistentes sociais estruturou-se em cinco eixos de análise/temas, nomeadamente: 1) Dados relativos à organização de enquadramento da ERPI; 2) Dados de caracterização/elementos relativos ao assistente social; 3) Caracterização geral da população sénior com quem o profissional trabalhava; 4) Vertentes da participação das pessoas idosas na dinâmica/estratégia institucional e nas atividades institucionais; 5) Implicações (oportunidades e constrangimentos) associadas à envolvência colaborativa.

Por sua vez, a entrevista aplicada às pessoas idosas enquadrou três eixos de análise, a saber: 1) Dados de caracterização/elementos relativos ao perfil das pessoas idosas a residir em ERPI; 2) Vertentes da participação das pessoas idosas em ERPI; 3) Implicações (oportunidades e constrangimentos) associadas à envolvência colaborativa.

\section{Procedimentos de análise dos dados}

O tratamento e interpretação dos dados beneficiou da técnica de análise de conteúdo, seguindo a abordagem temática categorial, sendo esta uma das técnicas de tratamento de informação, das mais comuns nas investigações empíricas realizadas nas diferentes ciências humanas e sociais (Bardin, 2016; Vala, 1990). Nos termos de Bardin (2016), esta técnica permite fazer uma descrição objetiva, sistemática e quantitativa do conteúdo manifestado das comunicações, tendo por objetivo efetuar inferências, com base na explicitação das mensagens cujas características careceram de inventariação e sistematização interpretativa. Esta investigação seguiu aquilo que são, segundo Vala (1990), as várias etapas de análise de conteúdo: a) desde a delimitação do quadro de referência teórica (i.e., delimitação dos conceitos analíticos); b) a constituição do corpus da análise, englobando todos os documentos-fonte que foram selecionados tendo por base os objetivos da análise do estudo; c) desenho das categorias e subcategorias e; d) a definição das unidades de registo, unidades de contexto e unidades de enumeração.

Os recortes apresentados foram selecionados tendo por base uma leitura compreensiva das entrevistas. Após essa leitura procedeu-se a uma análise mais aprofundada e posterior categorização e subcategorização. Neste caso, foi possível categorizar cinco categorias de análise decorrente do guião usado junto das assistentes sociais e duas categorias de análise decorrente do guião usado junto das pessoas idosas. Estas categorias emergiram do conteúdo manifesto presente nas entrevistas, neste caso, das ações e discrições das pessoas idosas, bem como das assistentes sociais. 


\section{Resultados}

A análise de conteúdo das entrevistas dos 17 participantes (EPI1 - EPI12: pessoas idosas auscultadas; EAS13 EAS17: assistentes sociais auscultadas) resultou numa análise compreensiva das entrevistas, que tornou possível categorizar em unidades de sentido decorrente dos guiões usados com vista à colheita de dados juntos das pessoas idosas e das assistentes sociais. As Tabelas 2 e 3 apresentam um compêndio das categorias mais relevantes para o domínio deste trabalho.

\section{Tabela 2}

Categorias e Unidades de Sentido da Participação das Pessoas Idosas em ERPI Decorrentes dos Contributos das Assistentes Sociais Auscultadas

\begin{tabular}{ll}
\hline Categoria & Unidade de Sentido
\end{tabular}

Heterogeneidade da(s) velhices(s) em ERPI

"Dar continuidade ao projeto de vida dos residentes e tentar ir ao encontro das particularidades de cada um" (EAS13); "eles não são todos iguais, e não podemos estar aqui a caracterizar e justificar que todos gostam da mesma coisa" (EAS14); "então vamos ter de adaptar serviços... não é o facto de entrar para uma instituição que deixa de ser ele próprio, deixa de ter os gostos dele, deixa de ter a voz dele" (EAS15).

Postura passiva das pessoas idosas face ao seu envolvimento: "querem estar no seu cantinho

Participação das pessoas idosas e manifestação de opiniões sossegadinhos "(EAS16); “Acho que os idosos não têm interesse (...) Porque se isolam muito... os idosos aqui são muito individuais" (EAS10); "temos algumas pessoas que têm este discurso "- Eu vim para aqui não é para trabalhar" (EAS13); "às vezes por preguicite aguda ou por comodidade, elas acabam por não o fazer" (EAS17).

Espaços de partilha (i.e., comissões de residentes): "É claro que cada uma dava as suas opiniões, sobre qualquer motivo" (EAS12); "onde eles partilham o que gostam, o que não gostam" (EAS13); "não só

Envolvência colaborativa (por para a programação de atividades lúdicas, mas também para perceber a satisfação, ou não, dos via da opinião das pessoas idosas) associada à participação em ERPI cuidados que são prestados" (EAS14); "nós até incentivamos que eles participem" (EAS15); "periodicamente pedimos a opinião deles" (EAS16).

Vantagens decorrentes da auscultação das opiniões das pessoas idosas: "Sentem-se ouvidos, respeitados, e para eles dá-lhes algum poder acrescido" (EAS13).

Ações atípicas: "fizemos um workshop... sobre o Estatuto do Maior Acompanhado e tivemos os residentes lá... vamos ter um workshop... acerca da ética e os cuidados que no fim de vida... eu não tenho dúvidas que nós vamos ter também residentes" (EAS13); "Organizamos com frequência comissão de residentes... fazemos reuniões multidisciplinares semanalmente... Os familiares também Inovação e conformismo das são convocados para essas reuniões, geralmente quando há uma situação que foge do trâmite normal ERPI em termos de ações várias aqui da instituição... sessões de biblioterapia... tertúlias... sessões de psicoeducação" (EAS14).

Orientações institucionais ajustadas com maior ou menor flexibilidade: "esta casa para funcionar também tem de ter regras... que têm de ser cumpridas" (EAS14); "era bom mudarmos estes horários tão rígidos das instituições... depende também do que eles nos solicitem" (E15); "Existe o envolvimento deles [pessoas idosas] sim. Existe sempre!" (EAS16); "Aqui elas [as residentes] têm tido a liberdade" (EAS17).

"é fazê-los [às pessoas idosas] ver, sentir e transpirarem que eles continuam a ser pessoas com direitos e com deveres e com vontades, [e] é eles perceberem que ainda são donos de si próprios e do património deles" (EAS13); "trabalharmos todos para o mesmo objetivo, e neste caso falo especificamente das ajudantes de lar... Passa muito por aqui o serviço de educação"(EAS14); “o trabalhar com o idoso, do capacitá-lo, do dar-lhe uma voz" (EAS15); "É fazer manifestar toda essa vivência" (EAS16); “lutar sempre para garantir o máximo de dignidade das utentes" (EAS17). 


\section{Tabela 3}

Categorias e Unidades de Sentido da Participação das Pessoas Idosas em ERPI decorrentes dos Contributos das Pessoas Idosas Auscultadas

\begin{tabular}{ll}
\hline Categoria $\quad$ Unidade de Sentido \\
\hline
\end{tabular}

Opiniões subvalorizadas pelo "bom funcionamento": "Ninguém dá a sua opinião... Está tudo bem!" (E1); "A gente não se mete nessa vida... Elas [elementos da Equipa Técnica] não trabalham ao ponto de a gente achar mal" (EPI3); "Não sinto o porquê de necessidade disso" (EPI10).

Opiniões não verbalizadas para evitar conflitos: "que eu tenha iniciativa própria, acho que não devo ser eu a fazer" (EPI5)"; "Não digo... Porque não quero barulho. Porque aquela que fala é que fica mal" (EPI7); "Às vezes dava a opinião e ainda ficava mal visto" (EPI8); "Não, não. Nunca faço queixa de ninguém... para não prejudicar os outros" (E 9); "eu acho que não se pode dar aqui muitas opiniões...

Participação das pessoas Porque eu sinto que há medo" (EPI11).

idosas e manifestação de opiniões

Opiniões transmitidas com sentido positivo: "Se tenho alguma observação a fazer nunca num sentido negativo" (EPI6); "Gosto, gosto [de dar opinião]" (EPI9).

Opiniões com cunho conciliador ou de minimização de conflitos: "Dizemos às próprias idosas que não sejam assim para as meninas" (EPI3); "Não. É o respeito que tenho pelas pessoas" (EPI10).

Postura passiva das pessoas idosas face ao seu envolvimento: "próprias pessoa que vivem aqui que tem relutância com algumas atividades e também não lhes apetece colaborar" (EPI5); "querem estar no seu cantinho sossegadinhos "(EPI16); "Acho que os idosos não têm interesse (...) Porque se isolam muito... os idosos aqui são muito individuais" (EPI10).

Espaços de partilha (i.e., comissões de residentes): "É importante para saberem se estamos satisfeitos, se está tudo a correr bem, e quanto a mim é importante" (EPI4). "dou a minha opinião às outras pessoas. Digo aos técnicos acerca das atividades" (EPI5). "Quando estamos em reuniões digo aquilo que penso" (EPI6); "vejo que as situações são resolvidas" (EPI10); "na reunião desabafamos daquilo

Envolvência colaborativa (por que não estava bem"; (EPI11); “É claro que cada uma dava as suas opiniões, sobre qualquer motivo" via da opinião das pessoas (EPI12).

idosas) associada à

participação em ERPI

Vantagens decorrentes da auscultação das opiniões das pessoas idosas: "Exercitar o cérebro é muito importante... a nossa cabeça está ocupada com coisas boas... Porque estamos a desenvolver" (EPI1, EPI3, EPI4); "Sinto-me bem a nível psicológico, fisiológico, a nível de bem-estar" (EPI5); "Sou encarada como pessoa humana liberta quando deito cá para fora o que penso" (EPI6)"; "Porque é um dever que a gente tem. Um voto em branco não serve" (EPI8); "sinto-me feliz...sinto-me realizada" (EPI9, EPI10, EPI11).

\section{Discussão}

A amostra das pessoas idosas, nos termos de Smith (2002) e Baltes e Smith (2003), faz sobressair os participantes do estudo no perfil da terceira idade, privilegiando a dimensão física e a funcionalidade sensorial e intelectual do indivíduo. Este facto encontra paralelo naquilo que tem de ver com a tomada de decisão relativa à institucionalização, na medida em que a maioria assumiu todo o processo inerente ao ingresso em ERPI, o que faz revelar elevados indicadores de autodeterminação e poder sobre si próprio. Posturas desta natureza desafiam as visões tradicionais associadas às pessoas idosas, principalmente residentes em ERPI, como sendo incapazes de exercer qualquer grau de controle sobre a sua de vida (Reed et al., 2003). Não obstante, é preciso ressalvar que em grande medida, de acordo com Reed e seus colegas (2003), o exercício da autonomia decisória das pessoas idosas na escolha da ERPI para a qual vão viver se deve sobremaneira: a) a estarem cientes dos seus direitos e escolhas; b) serem capazes de comunicar e debater essas escolhas e c) serem capazes de avaliar a informação que Ihes é fornecida. 
A par, o estudo assinala, de forma distintiva, uma maior presença de participantes do sexo feminino. Neste sentido, a feminização da velhice, neste caso ERPI, advém da maior esperança média de vida, aumentando, naturalmente, com o avançar na idade (Daniel et al., 2012; INE, 2012; Smith, 2002). Com efeito, como nos informa a Carta Social relativa a 2018 (Gabinete de Estratégia e Planeamento [GEP], 2018), do total de beneficiários que frequentava estruturas residenciais, cerca de $50 \%$ dos utilizadores era composto por pessoas idosas com 80 ou mais anos, o que visibiliza uma institucionalização da população idosa em idades muito avançadas, similarmente à investigação por nós conduzida. A este dado há a acrescentar uma descoberta não prevista inicialmente que tem de ver com o facto de estarmos a tratar de uma amostra que comporta essencialmente mulheres idosas capazes de exercer a sua autonomia decisória, algo surpreendente considerando que estamos a tratar de uma geração onde as mulheres por defeito não tomam decisões (Daniel et al., 2012; Fernandes, 2009).

No que se refere ao estado civil, constata-se no estudo que a presença em instituição tende a ser fortemente marcada por pessoas idosas que experienciam o estado civil de viúvo(a), dado que segue a tendência já explanada na Carta Social de 2018 (GEP, 2018). A variável concernente às habilitações literárias denuncia valores percentuais mais expressivos nos níveis de escolarização referentes ao 1ำciclo, facto comprovado pela Pordata (2020d) quando dá conta de no ano de 2019 ser este o ciclo de estudos mais expressivo de entre os demais no coletivo de pessoas com 65 ou mais anos. Este facto não negligenciável sustenta a necessidade de desenvolvimento de estudos que abranjam maior percentagem de pessoas idosas com níveis educativos mais avançados, alargando, assim, a melhor compreensão acerca do perfil que se avizinha/perspetiva da população idosa.

A abordagem referente à heterogeneidade da(s) velhice(s) em contextos residenciais demonstra que as ERPI estão convergentes com as abordagens teóricas associadas ao EA e amplamente explanada por diversos especialistas (Brandão et al., 2017; Luz, 2017; Marchand, 2017; Marier \& van Pevenage, 2017; Reed et al., 2003), que distinguem a pessoa idosa como um todo individual, contínuo e não estático, como preditores à adaptação do ato do cuidado, tal como no desenho do projeto de vida, o que sugere uma maior qualidade de vida na idade avançada.

Quanto aos elementos referentes à participação das pessoas idosas e à manifestação de opiniões naquilo que são os processos decisórios das ERPI, percebe-se que existe, em parte, uma tendencial propensão para que as pessoas idosas renunciem voluntariamente à tarefa de contribuir para as decisões alocadas às dinâmicas/estratégias institucionais (i.e., assumem uma postura mais passiva). Esta atitude, algo sedentária, protagonizada pelas pessoas idosas encontra paralelo, nos termos de Herazo-Beltrán e seus colegas (2017), com o facto de a experienciação da vida em ambientes institucionais dedicados à população mais envelhecida ser preditiva à dependência. Cenários desta natureza tendem a engrandece fenómenos idadistas e paternalistas (Azeredo, 2016; Pinto, 2013). Não obstante, estas evidências contrastam com a ocorrência de pessoas idosas que manifestam as suas opiniões a interlocutores vários, por forma a mitigar algum tipo de conflito e/ou efeito negativo (i.e., pessoas idosas mais pró-ativas). Parece poder concluir-se, tal como já sugerido por Reed e seus colegas (2003), que em ERPI existem pessoas idosas que se enquadram numa lógica mais exógena (i.e., assumindo uma feição mais diretiva/paternalista ou dirigida pelos profissionais) e outras numa lógica mais endógena (i.e., assumindo uma postura mais espontânea e de autênticos agentes sociais).

Num outro domínio de análise, os resultados mais benéficos às pessoas idosas encontram explicação nos ganhos que estão associados à concretização de espaços coletivos de partilha (e.g., comissões de residentes), enquanto espaços alternativos à convenção social normalizadora e modelos rígidos de atuação (Luz, 2017). Pressupõe-se com metodologias desta natureza, a ocorrência de uma participação interativa assente numa ótica dialógica entre pessoas idosas e profissionais com vista à reformulação de planos e formulação de novas ações tendo por base os 
contributos das pessoas idosas. Trata-se, portanto, de considerar e reconhecer a pessoa idosa que vive em contexto de ERPI enquanto co-designer da dinâmica institucional e, inclusive, no seu projeto de vida. Nesta matéria, os dados recolhidos parecem induzir-nos ao facto de um dos pilares mais fortes e sólidos que sustenta a satisfação das pessoas idosas, advém da oportunidade que lhes é dada de exercerem quotidianamente a sua cidadania (Dehi \& Mohammadi, 2020; Gustavsson et al., 2015; Luz, 2017; Marchand, 2017).

Complementarmente, e no que concerne à análise do cunho inovador e/ou conformista das ERPI em termos de ações de intervenção várias, foi possível constatar que as ERPI apesar de ainda assumirem modelos diretivos, naquilo que é o desenho e concretização de ações, começam a emergir disposições que apresentam um carácter mais inovador (e.g., comissões de residentes, workshops com e para as pessoas idosas, reuniões multidisciplinares com familiares, sessões de biblioterapia, sessões de psicoeducação, tertúlias). Desta forma, sem que se assuma uma tendencialização e representatividade, os factos suprarreferidos poderão induzir-nos ao início de uma nova e renovada corrente de atuação em ambientes institucionais que tende a assumir o exercício da autonomia decisória das pessoas idosas como um lugar de negociação de ações políticas, interativas e dinâmicas. Ou seja, parece-nos que começa a surgir, ainda que de forma tímida, abordagens operativas capazes de implicar ativamente os contributos das pessoas idosas (e.g., as opiniões), bem como o conhecimento que estas detêm advindo da sua experiência de vida. Esta matéria já tinha sido algo explorada em 2003 por Reed e seus colegas, tendo estes antevisto ser imperioso dar destaque às escolhas, decisões, opiniões e avaliações das pessoas idosas em ambientes residenciais.

\section{Conclusões}

Este estudo descreve como as pessoas idosas e as ERPI (representadas pelos profissionais de Serviço Social) percecionam e operacionalizam o exercício da autonomia decisória em ambientes residenciais nas decisões internas institucionais e no seu projeto de vida. Apurou-se que os desafios na atuação em ERPI versam precisamente naquilo que são as guidelines de ação mais recente associadas ao EA. Ou seja, o exercício quotidiano de cidadania, a manutenção de ações preventivas naquilo que é o cuidado individualizado, a produção de discursos emancipadores referente aos cuidados das pessoas idosas e a cedência de poder às pessoas idosas, induz-nos que a perspetiva da(s) velhice(s) deve ser múltipla e metamorfósica. Assim, estes resultados mostramnos, em termos de interpretação, da existência, por parte das ERPI, de uma gradual perceção da velhice e do envelhecimento como um processo e uma construção social que segue as alterações societais, assumindo estas graduais diferenças em termos de perceção da institucionalização e das condições de vivência associadas às estruturas residenciais.

Agradecimentos | Acknowledgements: Agradece-se a todos as pessoas idosas e assistentes sociais que participaram nesta investigação, bem como às direções e administrações das ERPI por terem permitido realizar esta investigação.

Conflito de interesses | Conflict of interest: nenhum | none.

Fontes de financiamento | Funding sources: nenhuma | none. 


\section{Referências}

Alaphilippe, D., \& Bailly, N. (2014). Psicologia do adulto idoso. Edições Piaget.

Almeida, H. (2017). Participação como eixo estratégico renovado na intervenção social. In C. Albuquerque \& A. C. B. Arcoverde (Coord.), Serviço social contemporâneo. Reflexividade e estratégia (pp. 47-70). PACTOR - Edições de Ciências Sociais, Forenses e da Educação.

Azeredo, Z. (2016). Cultura, cidadania e envelhecimento. In Z. Azeredo (Coord.), Envelhecimento, cultura e cidadania (pp. 67-73). Edições Piaget.

Baltes, P. B., \& Smith, J. (2003). New frontiers in the future of aging: From successful aging of the young old to the dilemmas of the fourth age. Gerontology, 49, 123-135. https://doi.org/10.1159/000067946

Bardin, L. (2016). Análise de conteúdo. Edições 70.

Birren, J. E. (1995). New models of aging: Comment on need and creative efforts. Canadian Journal on Aging, 14(1), 13. https://doi.org/10.1017/S0714980800010424

Brandão, D., Ribeiro, Ó., \& Paúl, C. (2017). Functional, sensorial, mobility and communication difficulties in the Portuguese oldest old (80+). Acta Médica Portuguesa, 30(6), 463-471. https://doi.org/10.20344/amp.8060

Cabral, M. (2017). O envelhecimento sociodemográfico e os seus riscos. In P. M. Ferreira, M. V. Cabral, \& A. Moreira (Org.), Envelhecimento na sociedade portuguesa. Pensões, família e cuidados (pp. 99-109). Imprensa de Ciências sociais.

Crispim, R. (2020). Ser-se pessoa (in)ativa em estruturas residenciais para idosos. O Serviço Social a favor da inclusão e ativação das pessoas idosas nas dinâmicas intrainstitucionais e no seu projecto de vida [Tese de mestrado não publicada]. Universidade de Coimbra.

Crispim, R. M. S., \& Almeida, H. N. (2019). Mediação social em gerontologia. Questionamentos atuais do serviço social em estruturas residenciais para pessoas idosas. In A. Neves, T. Riboira, I. Machado, \& M. S. Almeida (Coords.), III Congresso Ibero-Americano de intervenção social - Direitos Humanos e mediação (pp. 483-496). Lema d'Origem Editora.

Daniel, F., Simões, T., \& Monteiro, R. (2012). Representações sociais do «envelhecer no masculino» e do «envelhecer no feminino». Ex Aequo, 26, 13-26. https://bit.ly/2WJarNe

Dehi, M., \& Mohammadi, F. (2020). Social participation of older adults: A concept analysis. International Journal of Community Based Nursing and Midwifery, 8(1), 55-72. https://doi.org/10.30476/IJCBNM.2019.82222.1055

Dionigi, R. A. (2015). Stereotypes of aging: Their effects on the health of older adults. Journal of Geriatrics, 2015, Artigo 954027. https://doi.org/10.1155/2015/954027

Eurostat. (2019). Guia das estatísticas europeias. https://ec.europa.eu/info/statistics/guide-european-statistics_pt

Fagundes, K., Esteves, M., Ribeiro, J., Siepierski, C., Silva, J., \& Mendes, M. (2017). Instituições de longa permanência como alternativa no acolhimento das pessoas idosas. Revista Salud Pública, 19(2), $210-214$. https://doi.org/10.15446/rsap.v19n2.41541

Fernandes, J. M. N. (2011). O desafio do envelhecimento demográfico. Revista do Instituto Politécnico de Castelo Branco, 1(2), 5-11. https://repositorio.ipcb.pt/bitstream/10400.11/3074/1/R_IPCB2_1.pdf

Fernandes, M. G. M. (2009). Papéis sociais de gênero na velhice: o olhar de si e do outro. Revista Brasileira de Enfermagem, 62(5), 705-710. https://doi.org/10.1590/S0034-71672009000500009

Fonseca, A. (2006). O envelhecimento. Uma abordagem psicológica. Universidade Católica Editora.

Gabinete de Estratégia e Planeamento. (2018). Carta Social - Rede de serviços e equipamentos - Relatório 2018. http://www.cartasocial.pt/pdf/csocial2018.pdf

Gustavsson, M., Liedberg, G., \& Ranada, Å. (2015). Everyday doings in a nursing home - described by residents and staff. Scandinavian Journal of Occupational Therapy, 22(6), 435-441. https://doi.org/10.3109/11038128.2015.1044907

Hees, S., Horstman, K., Jansen, M., \& Ruwaard, D. (2015). Conflicting notions of citizenship in old age: An analysis of an activation practice. Journal of Aging Studies, 35, 178-189. https://doi.org/10.1016/j.jaging.2015.09.001 
Herazo-Beltrán Y., Quintero-Cruz M., Pinillos-Patiño Y., García-Puello F., Núñez-Bravo, N., \& Suarez-Palacio, D. (2017). Calidad de vida, funcionalidad y condición física en adultos mayores institucionalizados y no institucionalizados. Revista Latinoamericana de Hipertension, 12(5), 174-81. http://www.shorturl.at/nKLU1

Instituto Nacional de Estatística. (2019). Tábuas de mortalidade em Portugal. https://www.shorturl.at/pFPRZ

Instituto Nacional de Estatística. (2012). Censos 2011. Resultados definitivos - Portugal. https://www.shorturl.at/kuGN3

Júnior, F. B. A., Machado, I. T. J., Santos-Orlandi, A. A., Pergola-Marconato, A. M., Pavarini, S. C. I., \& Zazzetta, M. S. (2017). Fragilidade, perfil e cognição de idosos residentes em área de alta vulnerabilidade social. Ciência \& Saúde Coletiva, 24(8), 3047-3056. https://doi.org/10.1590/1413-81232018248.26412017

Laslett, P. (1994). The third age, the fourth age and the future. Ageing and Society, 14(3), 436-447. https://doi.org/10.1017/S0144686X00001677

Lima, M. (2010). Envelhecimento(s). Imprensa da Universidade de Coimbra.

Luz, H. (2017, setembro 5-9). Problemas sociais complexos - wicked problems - e intermediação das organizações de economia social: Estratégias adaptativas no campo do envelhecimento ativo (EA) [Apresentação de artigo]. XVIII Congreso Ahila en los márgenes de la historia tradicional. Nuevas miradas de América Latina desde el siglo XXI, Valencia, Espanha.

Marchand, I. (2017). Stories of contemporary aging: An analysis of 'lived' citizenship in later life. Journal of Gerontological Social Work, 61(5), 472-491. https://doi.org/10.1080/01634372.2017.1420001

Marier, P., \& van Pevenage, I. (2017). Three competing interpretations of policy problems: tame and wicked problems through the lenses of population aging. Policy and Society, 36(3), 430-445. https://doi.org/10.1080/14494035.2017.1361636

Medeiros, M. M. D. de, Carletti, T. M., Magno, M. B., Maia, L. C., Cavalcanti, Y. W., \& Rodrigues-Garcia, R. C. M. (2020). Does the institutionalization influence elderly's quality of life? A systematic review and meta-analysis. BMC Geriatrics 20. Artigo 44. https://doi.org/10.1186/s12877-020-1452-0

Mendes, F. R., Zangão, O. B., \& Mestre, T. S. (2018). Representações sociais da violência sobre idosos: Idadismo, estereótipos e discriminação. Revista Ibero-Americana de Saúde e Envelhecimento, 3(3), 1107-1127. https://doi.org/10.24902/r.riase.2017.3(3).1104

Mendes, M. (2017). Envelhecimento e fecundidade: uma antevisão do nosso futuro demográfico. In P. M. Ferreira, M. V. Cabral, \& A. Moreira (Org.), Envelhecimento na sociedade portuguesa. Pensões, família e cuidados (pp. 111-140). Imprensa de Ciências sociais.

Miguel, I. (2016). Mais idade, menos participação? Lógicas de "resgate" da cidadania na população idosa. In C. Albuquerque \& H. A. Luz (Coord.), Políticas sociais em tempos de crise. Perspetivas, tendências e questões críticas (pp. 193-208). Pactor.

Nações Unidas. (2002). Informe de la segunda asamblea mundial sobre el envejecimiento. Madrid. http://www.monitoringris.org/documents/norm_glob/mipaa_spanish.pdf

Nogueira, M., Lima, A., Trigueiro, J., Torquato, I. Henriques, M., \& Alves, M. (2016). Comparing the quality of life of institutionalized and non-institutionalized older adults. Uerj Nursing Journal, 24(5), 1-6. https://doi.org/10.12957/reuerj.2016.28185

Pinto, C. (2013). Uma prática de empowerment com adultos idosos. In M. I. Carvalho (Coord.), Serviço social no envelhecimento (pp. 49-65). PACTOR - Edições de Ciências Sociais, Forenses e da Educação.

Pordata. (2020a). População residente: total e por grandes grupos etários. Quantos são os jovens, os idosos ou as pessoas em idade ativa? https://www.shorturl.at/InOQ5

Pordata. (2020b). População residente com 65 e mais anos do sexo masculino, estimativas a 31 de Dezembro: total e por grupo etário. Quantos homens idosos existem no final do ano, por faixa etária? https://www.shorturl.at/zEU06

Pordata. (2020c). População residente com 65 e mais anos do sexo feminino, estimativas a 31 de Dezembro: total e por grupo etário. Quantas mulheres idosas existem no final do ano, por faixa etária? https://www.shorturl.at/npqv9

Pordata. (2020d). População residente com 15 a 64 anos e 65 e mais anos: por nível de escolaridade completo mais elevado. Quantas pessoas, em idade activa ou idosa, há sem instrução ou com o ensino básico, secundário ou superior? https://www.shorturl.at/dtFHP 
Rede Europeia Anti-Pobreza/Portugal. (2017). Estratégia nacional para o envelhecimento ativo e saudável $2017-2025$. https://bit.ly/2WGTgLV

Reed, J., Cook, G., Sullivan, A., \& Burridge, C. (2003). Making a move: Care-home residents' experiences of relocation. Ageing and Society, 23(2), 225-241. https://doi.org/10.1017/S0144686X02001101

Rosa, M. J. V. (2020). Um tempo sem idades. Ensaio sobre o envelhecimento da população. Tinta da China.

Rosa, M. (2018). Envelhecimento demográfico e desenvolvimento social. In M. C. P. Neves \& A. B. Felix (Coord.), Ética aplicada. Protecção social (pp. 299-319). Edições 70 - Edições Almedina.

Simões, A. L., \& Sapeta, P. (2017). Construção social do envelhecimento individual. Revista Kairós - Gerontologia, 20(2), 9-26. https://doi.org/10.23925/2176-901X.2017v20i2p09-26

Smith, J. (2002). The fourth age: A period of psychological mortality? In Max-Planck-Gesellschaft Zur Förderung der Wissenschaften \& Ernst Schering Research Foundation (Eds.), Biomolecular aspects of aging: The social and ethical implications, (pp. 75-88). Max Planck Forum.

Sousa, J. G., \& Batista, M. M. (2015). Ócio e cultura na (re)construção identitária de pessoas idosas institucionalizadas. Revista Subjetividades, 15(2), 275-286. http://www.shorturl.at/FGLQW

Stephens, C., Breheny, M., \& Mansvelt, J. (2015). Healthy ageing from the perspective of older people: A capability approach to resilience. Psychology \& Health, 30(6), 715-731, https://doi.org/10.1080/08870446.2014.904862

Vala, J. (1990). A análise de conteúdo. In A. S. Silva \& M. Pinto (Orgs.). Metodologia das ciências sociais (pp. 101-128). Edições Afrontamento.

Vieira, I. (2017). A participação. Um paradigma para a intervenção social. Universidade Católica Editora. 